\title{
Erratum to: High-resolution ultrasonography in assessment of nail-related disorders
}

\author{
R. Singh • D. Bryson - H. P. Singh • K. Jeyapalan • \\ J. J. Dias
}

Published online: 6 October 2012

(C) ISS 2012

\section{Erratum to: Skeletal Radiol}

DOI 10.1007/s00256-012-1426-1

The original version of this article requires an addendum. The article re-uses figures (Figs. 1A, 1C, 2A) that have been published before. The authors have obtained copyright information before publishing these figures but this was unfortunately not included in the article.

"These figures were published in Dermatology, 2nd edition, 9781416029991, Jean L Bolognia, MD, Joseph L Jorizzo, MD, Ronald P Rapini, MD (Authors), Chapter 67, Biology of nail, Figs $67.14 \& 67.15$, Copyright Elsevier (2008).”

The online version of the original article can be found at http://dx.doi.org/ 10.1007/s00256-012-1426-1.

R. Singh $\cdot$ D. Bryson $\cdot$ H. P. Singh $\cdot$ J. J. Dias

Department of Orthopaedics, Glenfield Hospital,

University Hospitals of Leicester NHS Trust,

Leicester, UK

K. Jeyapalan

Department of Radiology, Glenfield Hospital,

University Hospitals of Leicester NHS Trust,

Leicester, UK

J. J. Dias $(\bowtie)$

Department of Orthopaedic Surgery, Glenfield Hospital,

University Hospitals of Leicester,

Groby Road,

Leicester LE3 9QP, UK

e-mail: jd96@leicester.ac.uk 